\title{
The relative importance of various source regions on East Asian surface ozone
}

\author{
by Tatsuya Nagashima, Toshimasa Ohara, Kengo Sudo and Hajime Akimoto
}

\section{Supplementary Information}

Table S1. Contributions (ppbv) from source regions to receptor areas in East Asia averaged in spring (March-April-May) and summer (June-July-August) ${ }^{\mathrm{a}}$.

\begin{tabular}{|c|c|c|c|c|c|c|c|c|c|c|c|}
\hline & \multicolumn{6}{|c|}{$\begin{array}{c}\text { Receptor Area } \\
\text { KOR } \\
\end{array}$} & \multicolumn{4}{|c|}{$\mathrm{CHN}$} \\
\hline & & $\mathrm{N}$ & $\bar{E}$ & $\mathrm{~W}$ & $\bar{S}$ & $\bar{N}$ & $\bar{S}$ & $\mathrm{NE}$ & $\overline{\mathrm{NCP}}$ & YRB & SE \\
\hline \multirow{22}{*}{ 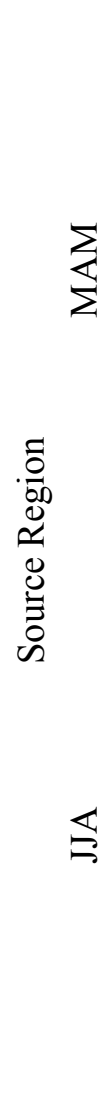 } & |JPN & 5.4 & 12.0 & 10.1 & 1.8 & 1.0 & 2.8 & 0.4 & 0.4 & 0.4 & 0.2 \\
\hline & $\mathrm{CHN}$ & 3.8 & 5.3 & 7.1 & 6.3 & 11.1 & 9.9 & 6.8 & 20.9 & 32.0 & 23.3 \\
\hline & KOR & 1.6 & 2.5 & 3.5 & 1.1 & 12.8 & 11.3 & 0.6 & 1.9 & 0.8 & 0.2 \\
\hline & Asea ${ }^{b}$ & 4.2 & 4.1 & 5.1 & 8.8 & 2.2 & 3.9 & 1.5 & 1.1 & 1.3 & 1.4 \\
\hline & ESB & 3.0 & 1.4 & 0.9 & 0.4 & 1.5 & 1.1 & 4.3 & 1.1 & 0.3 & 0.1 \\
\hline & IDC $+{ }^{b}$ & 0.3 & 0.4 & 0.7 & 2.1 & 0.3 & 0.4 & 0.3 & 0.4 & 2.3 & 8.2 \\
\hline & $\mathrm{RMT}^{\mathrm{b}}$ & 7.0 & 6.7 & 6.4 & 4.3 & 7.0 & 6.7 & 8.8 & 7.5 & 4.4 & 2.1 \\
\hline & MISC & 1.3 & 1.0 & 0.9 & 0.9 & 1.1 & 1.0 & 1.9 & 1.0 & 0.8 & 0.8 \\
\hline & FT & 5.4 & 6.3 & 6.7 & 7.7 & 5.8 & 5.9 & 6.1 & 6.6 & 6.3 & 6.9 \\
\hline & STR & 10.2 & 10.9 & 10.9 & 9.2 & 10.2 & 10.3 & 11.1 & 11.0 & 8.2 & 5.2 \\
\hline & TOTL & 42.1 & 50.7 & 52.3 & 42.6 & 53.0 & 53.4 & 41.8 & 52.0 & 56.8 & 48.3 \\
\hline & JPN & 10.6 & 19.8 & 14.0 & 1.0 & 1.4 & 4.1 & 0.6 & 0.3 & 0.4 & 0.2 \\
\hline & CHN & 3.2 & 3.9 & 4.3 & 2.2 & 12.6 & 8.4 & 14.2 & 37.9 & 38.0 & 21.8 \\
\hline & KOR & 2.0 & 1.8 & 1.7 & 0.2 & 21.7 & 16.8 & 1.2 & 3.2 & 0.7 & 0.1 \\
\hline & Asea $^{b}$ & 5.8 & 3.9 & 5.1 & 6.8 & 2.7 & 4.9 & 1.1 & 0.7 & 0.9 & 0.6 \\
\hline & ESB & 1.7 & 0.4 & 0.2 & 0.0 & 0.9 & 0.5 & 4.8 & 0.9 & 0.2 & 0.0 \\
\hline & IDC $+{ }^{b}$ & 0.3 & 1.0 & 1.6 & 3.3 & 0.6 & 1.2 & 0.1 & 0.5 & 2.3 & 6.7 \\
\hline & $\mathrm{RMT}^{\mathrm{b}}$ & 1.3 & 1.1 & 0.9 & 0.6 & 1.9 & 1.3 & 3.4 & 3.0 & 1.2 & 0.9 \\
\hline & MISC & 0.8 & 0.6 & 0.7 & 1.0 & 0.7 & 0.7 & 1.6 & 0.8 & 0.7 & 1.1 \\
\hline & FT & 4.8 & 6.8 & 7.5 & 8.8 & 7.1 & 6.8 & 8.1 & 8.7 & 7.4 & 8.0 \\
\hline & STR & 2.6 & 2.5 & 2.2 & 1.7 & 4.0 & 2.7 & 6.0 & 5.7 & 2.4 & 1.5 \\
\hline & TOTL & 33.4 & 41.9 & 38.3 & 25.5 & 53.6 & 47.4 & 41.0 & 61.7 & 54.0 & 40.9 \\
\hline
\end{tabular}

${ }^{a}$ All contributions are averaged for 6 years

${ }^{\mathrm{b}}$ ASea (Adjacent Sea) is the sum of NPC, JPS and ECS; IDC+ is the sum of IDC and IND; and RMT (ReMoTe) is the sum of AMN, EUR, CAS, MES and NAT 

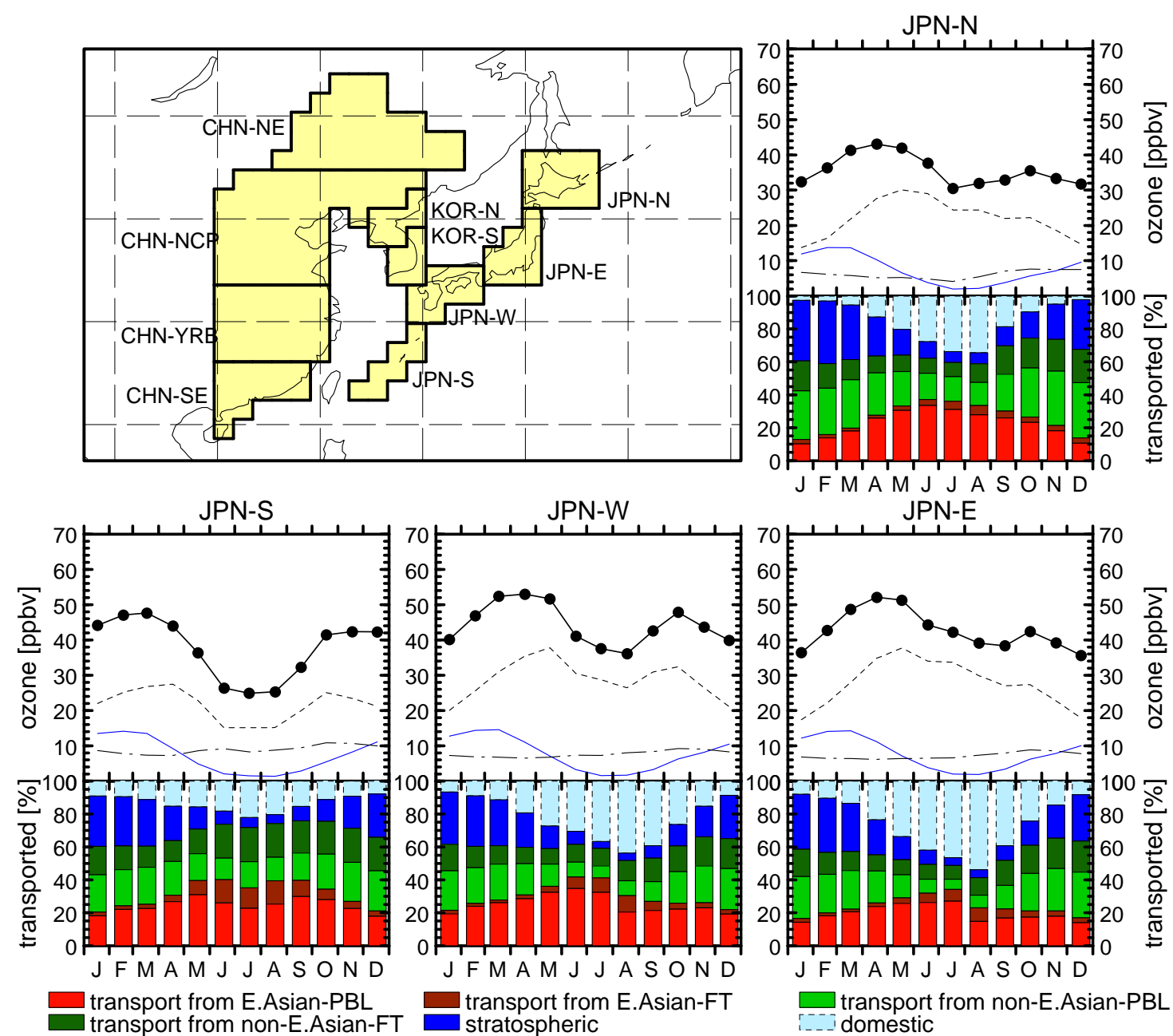

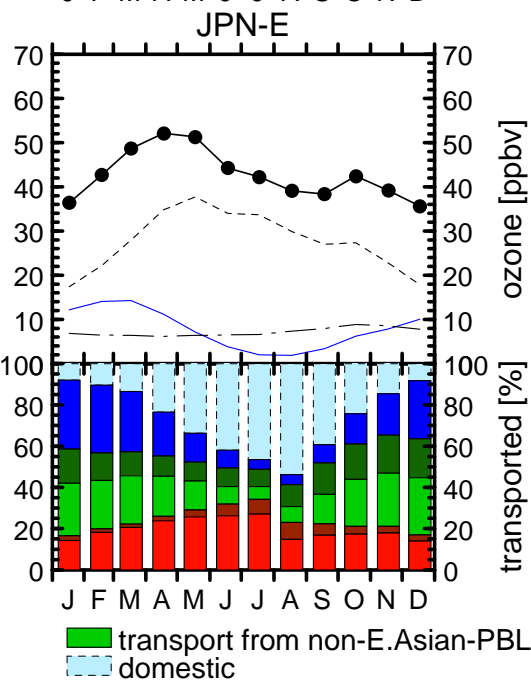

Figure S1. (Top plots of each figure) Seasonal variations of area-averaged monthly mean surface $\mathrm{O}_{3}$ with contributions from the stratosphere (blue solid lines), PBL (black dashed lines), and FT (black dash-dotted lines) calculated by the model. The map shows the areas of averaging. (Bottom plots of each figure) Red bars indicate the contribution $(\%)$ of $\mathrm{O}_{3}$ originating from PBL in East Asian source region, brown bars from FT in East Asia, green bars from non-East-Asian PBL, dark green bars from non-East-Asian FT, blue bars from stratosphere and pale blue bars from domestic pollution. All values are averaged for 6 years. 

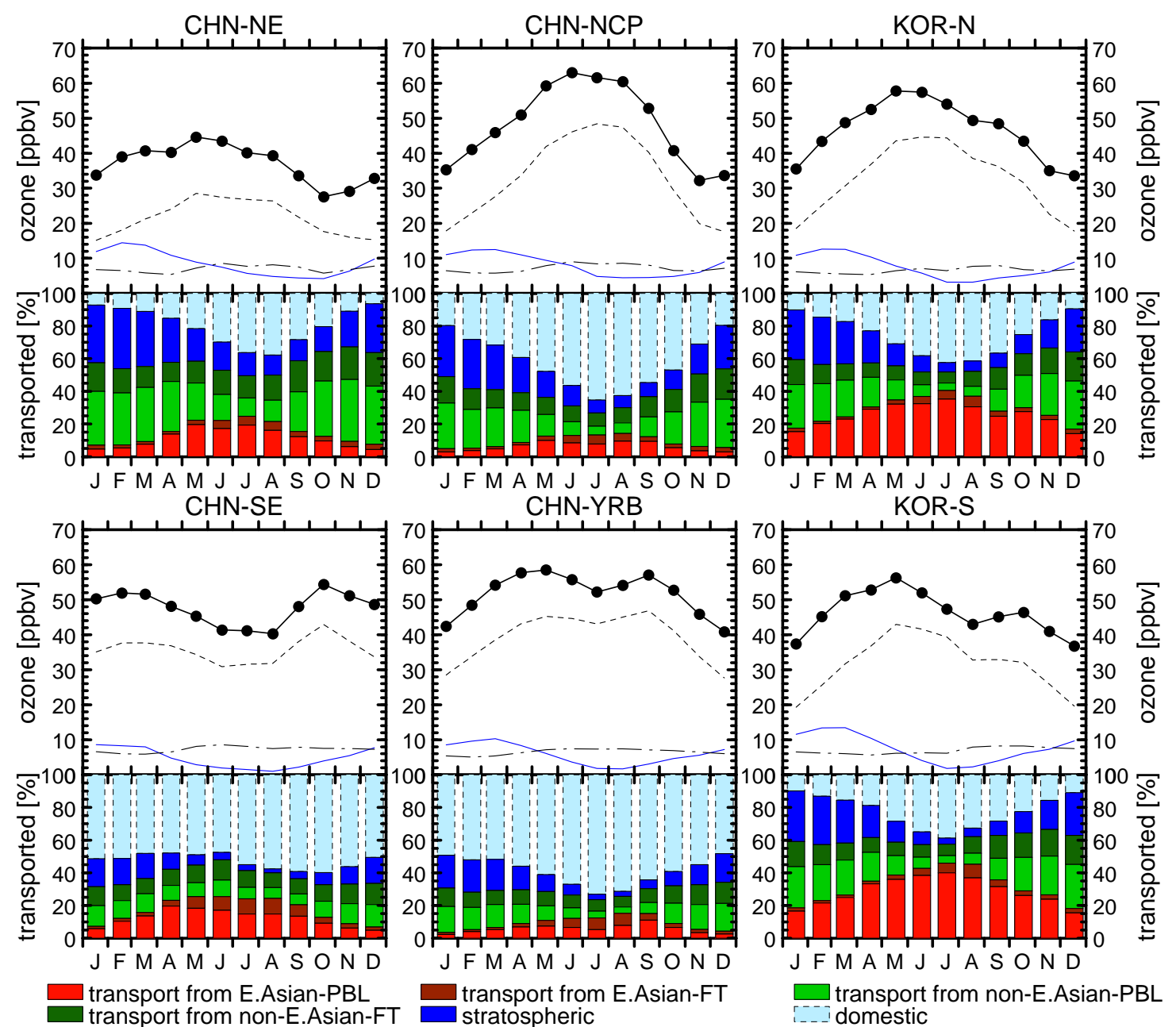

Figure S1. (continued) 

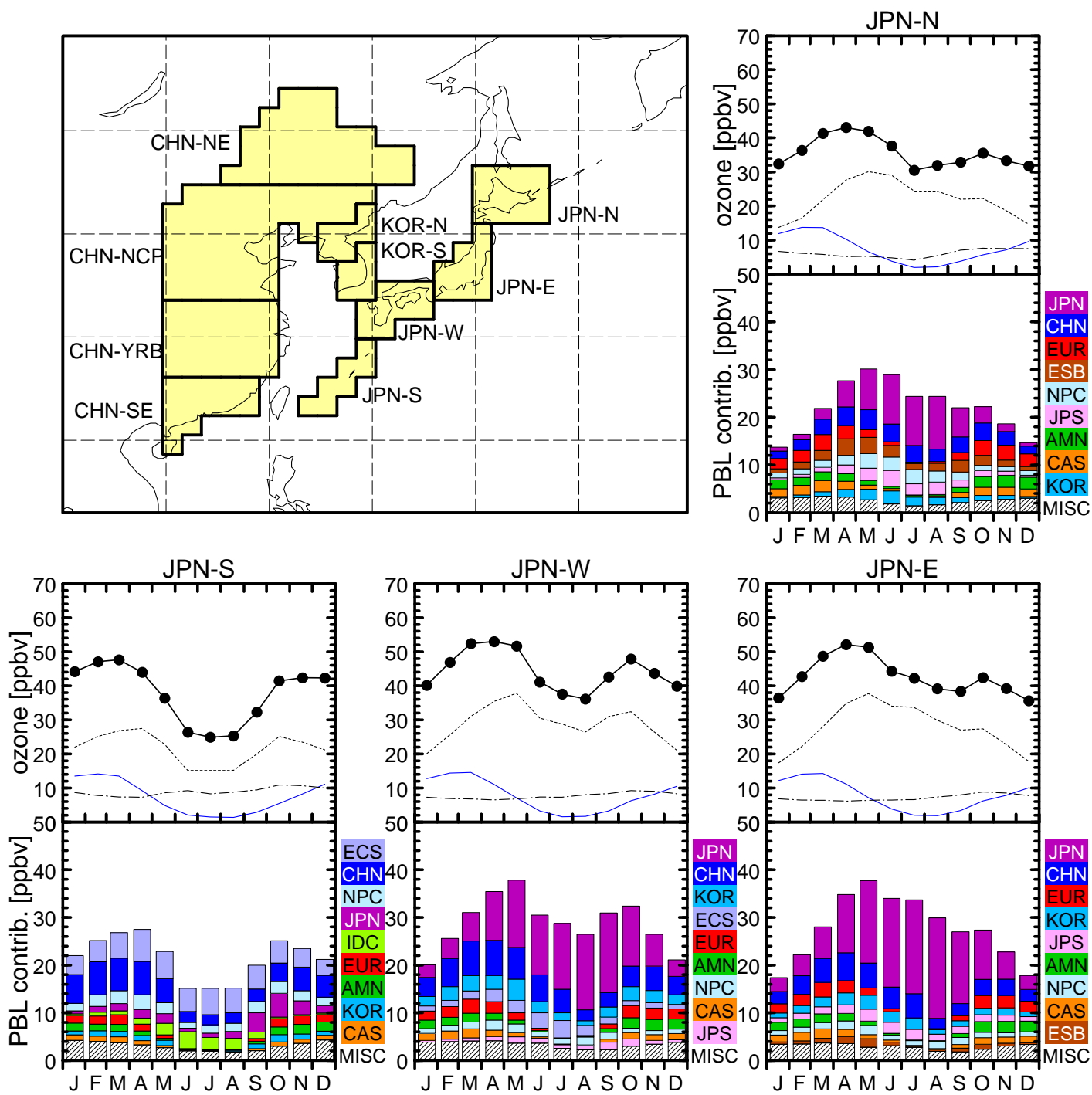

Figure S2. (Top plots of each figure) Seasonal variations of area-averaged monthly mean surface $\mathrm{O}_{3}$ with contributions from the stratosphere (blue solid lines), PBL (black dashed lines), and FT (black dash-dotted lines) calculated by the model. The map shows the areas of averaging. (Bottom plots of each figure) Contributions (ppbv) from the top nine source regions in the PBL and the sum of the rest of the PBL (MISC) are shown as stacked bar charts. Coloured boxes with the region names are stacked from top to bottom in order of annual mean contribution. All values are averaged for 6 years. 

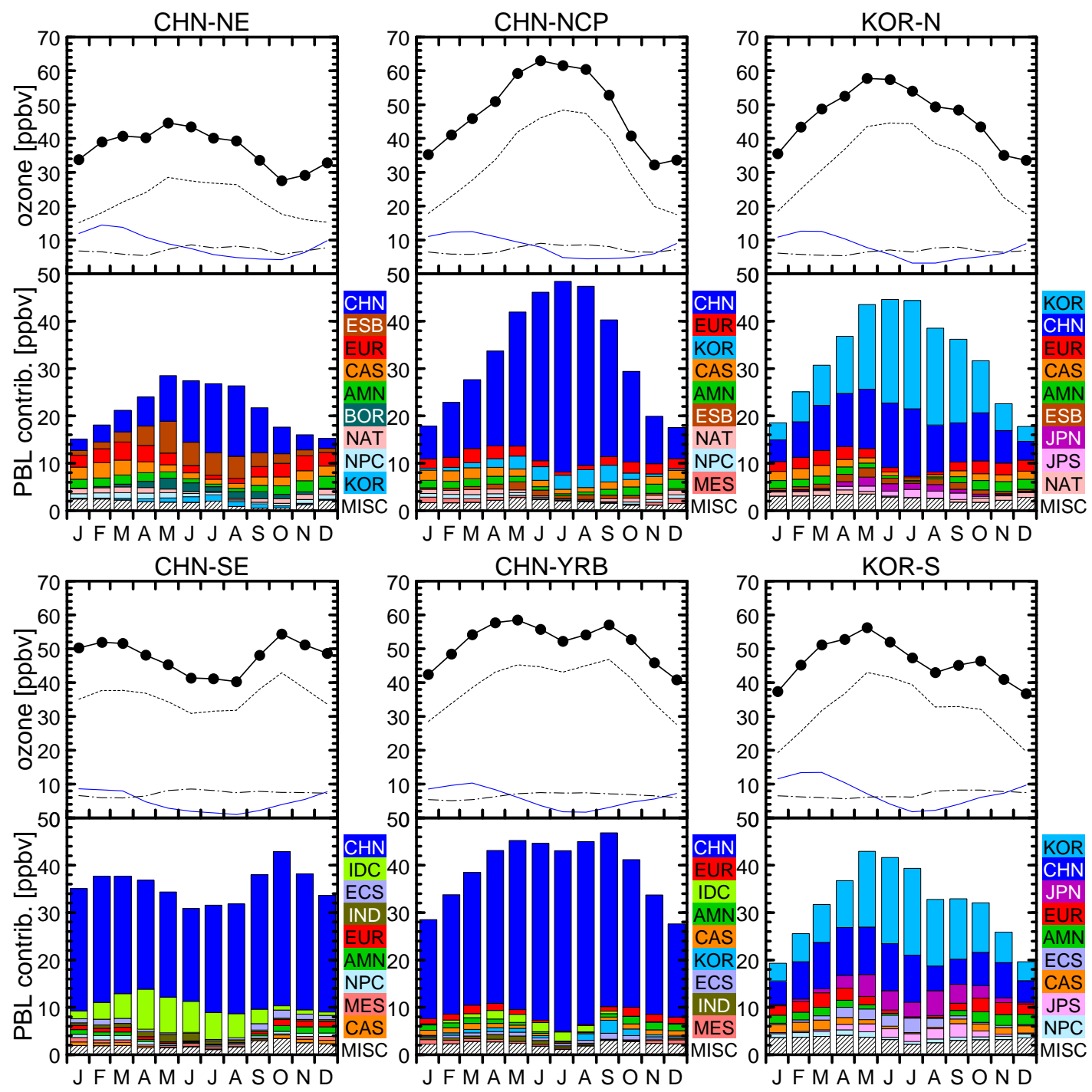

Figure S2. (continued) 